\title{
Limits of Environmentally Friendly Transport
}

\author{
I. Drahotský \\ Jan Perner Transport Faculty, University Pardubice \\ *Corresponding author: ivo.drahotsky@upce.cz
}

\author{
A. Peltrám \\ Banking College, Prague, Czech Republic
}

\begin{abstract}
For railway transport to be more environmentally friendly than road transport it is necessary to reach more than the minimum occupancy and load in passenger trafficking and in freight trafficking respectively. It is not of great use to compare average values, e.g., of consumption of energy and emissions of elements of greenhouse gases; a better option is to compare the consumption of fuel per passenger and the same in the case of emissions. When comparing two vehicles of the same or comparable modes of transport (buses, railway units) in local and regional passenger traffic we can describe, with an acceptable simplification, the point of intersection of two lines of both consumption and emissions.
\end{abstract}

KEY WORDS: transport, environment.

\section{MYTHS AND REALITY}

There is a deep-rooted hypothesis that there is a general, environmentally greater friendliness of railways in comparison with road transport, irrespective of the volume of goods in goods trains and occupied passenger trains. This is presented in many studies mentioned in [3].

Sufficiently used trains are more likely connected with block trains, passenger trains for commuting in large conurbations, or in the case of long haulage where the probability of gather goods or passengers is higher. But it is not always the case for regional and local railways. They began operating at the end of the 19th or at the beginning of the 20th century, when the only competitors of railways could be navigable inland waterways and horse-drawn carriages. Despite the imposing development of railway technology, the shift from carter's business to lorries has been more impressive. And there has arisen much tougher competition from the side of cars.

The new feature in modal split in transport has led to many comparisons of the consumption of energy in modes of transport and emissions - together with rates of accidents - as the most important indicators of the effects of transport on the environment.

The problem of changed modal split in the case of regional and local railway lines and road transport has been that it is usually primarily illustrated using the consumption of fuel of fully, or supposed high-occupancy, trains with buses or cars. But the local trains are not always occupied enough. Therefore the more predicative indicators could be the specific consumption - consumption per passenger or per tonne of goods carried. 
We suppose, with some simplification, the linearity of consumption of fuel and weight of occupied vehicle. It is possible in the first approximation to omit goods' traffic that is rather poor on the Czech local and regional railways. (In which European countries is it similar?)

With some simplification of the supposed linearity (it is true for predominant parts of curves of occupation and consumed fuel, but not for whole of course) we could describe the relations of weight - consumption of fuel/emissions and, in a similar way, the emissions of greenhouse gases, as two sloping straight lines and to find points of intersection of these two lines. On axis $x$ there is the number of passengers in a train, bus, and car; on axis y consumption of fuel and the same is valid in the case of dependence of the consumption of fuel exhaust - gas- emissions. The vehicle with higher capacity has, as a rule, higher consumption than the vehicle with lower capacity. The point of intersection defines the minimum number of passengers for the vehicle with higher capacity (e.g. train to bus) to be more efficient regarding the consumed energy than the vehicle with lower capacity.

In Figure 1 there is a graph of a comparison of the consumption of fuel (and analogously of emissions) of two modes of transport with different capacities (the most widespread railway unit series 800 or 810 of the Czech Railways and the standard buses Karosa; they both have about 44 seats and we suppose the same running speed.

We compare the most common types of train units for local and regional lines and buses in the case of vehicles with approximately the same capacity of occupation - and we have found the lower number of passengers more than 17 or 18 passengers in case of the originally used engine some decades ago at the time of production of railway units and more than 12 passengers in case of replaced engines of the latest construction.

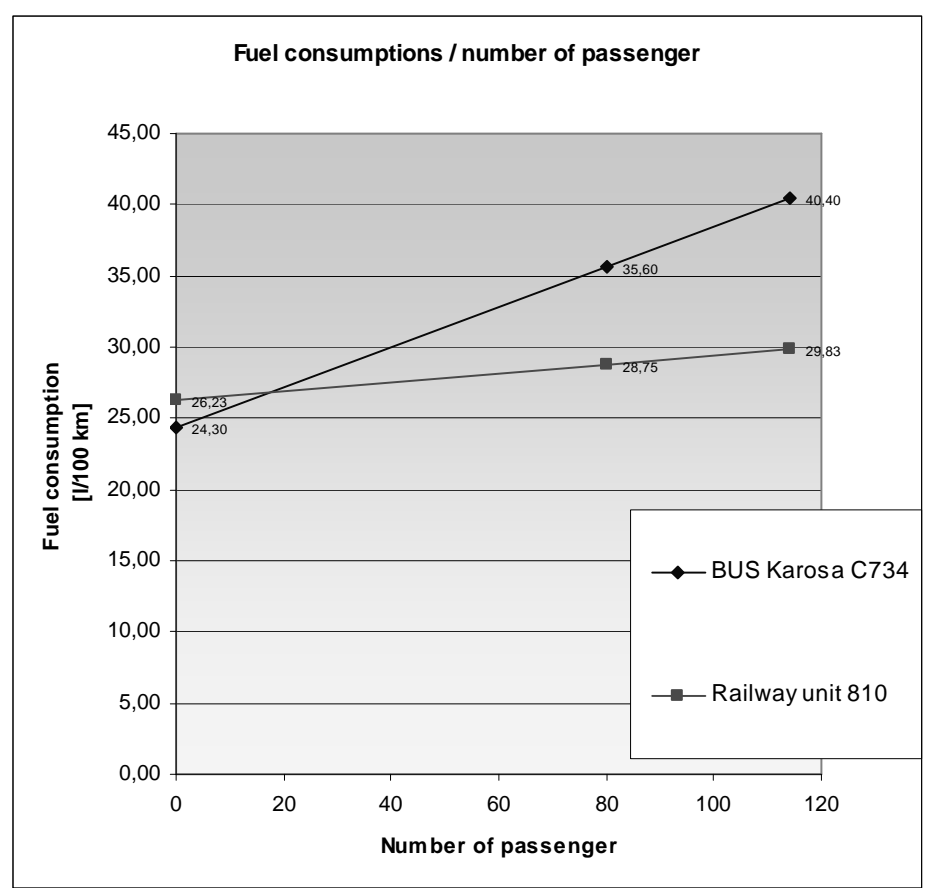

Figure 1: Comparison of fuel consumption per passenger of BUS Karosa C734 and Railway 810 
Table 1: Equations of fuel/passenger

\begin{tabular}{|l|l|}
\hline Type of vehicle & Equation of straight line in the slope form \\
\hline Karosa C 734 & $\mathrm{Q}[\mathrm{l}]=24,30+0,141 \mathrm{p}$ [pass] \\
Karosa C 732 & $\mathrm{Q}[\mathrm{l}]=24,89+0,14 \mathrm{p}$ [pass] \\
Karosa C 934 & $\mathrm{Q}[\mathrm{l}]=24,41+0,142 \mathrm{p}$ [pass] \\
Articulated bus & $\mathrm{Q}[\mathrm{l}]=32,23+0,146 \mathrm{p}$ [pass] \\
810 solo & $\mathrm{Q}[\mathrm{l}]=26,23+0,031 \mathrm{p}$ [pass] \\
$810+1$ towed c. & $\mathrm{Q}[\mathrm{l}]=34,31+0,032 \mathrm{p}$ [pass] \\
\hline
\end{tabular}

In the Figures below there is a graph of comparisons of the same vehicles regarding the estimated values of emissions. There were some problems with the compatibility of recalculated emissions - within the automotive industry CO is often used. But from the year 2013, supposing international agreement to the follow-up of the Kyoto protocol, transport should be included into the European scheme of trading emissions, where the main common denominator will be CO2. It was very difficult to find coefficients of conversion of all greenhouse gases, either into $\mathrm{CO}$ or into $\mathrm{CO} 2$, and to have the same mix of exhaustemissions.

There was another possibility to use estimates published in the Handbook of estimation of external costs in the transport sector.

At the very end of our work the amended proposal of the new directive, confirmed by the official improvement of this Directive at the end of April in Luxembourg and supporting greater extension of "green" road vehicles and a reduction in consumption, had been approved. Results are in the following Tables (Figures). All situational possibilities are presented. We can find the limit of passengers only when the line also cuts the axis of the quadrant (figure 3 and 4).

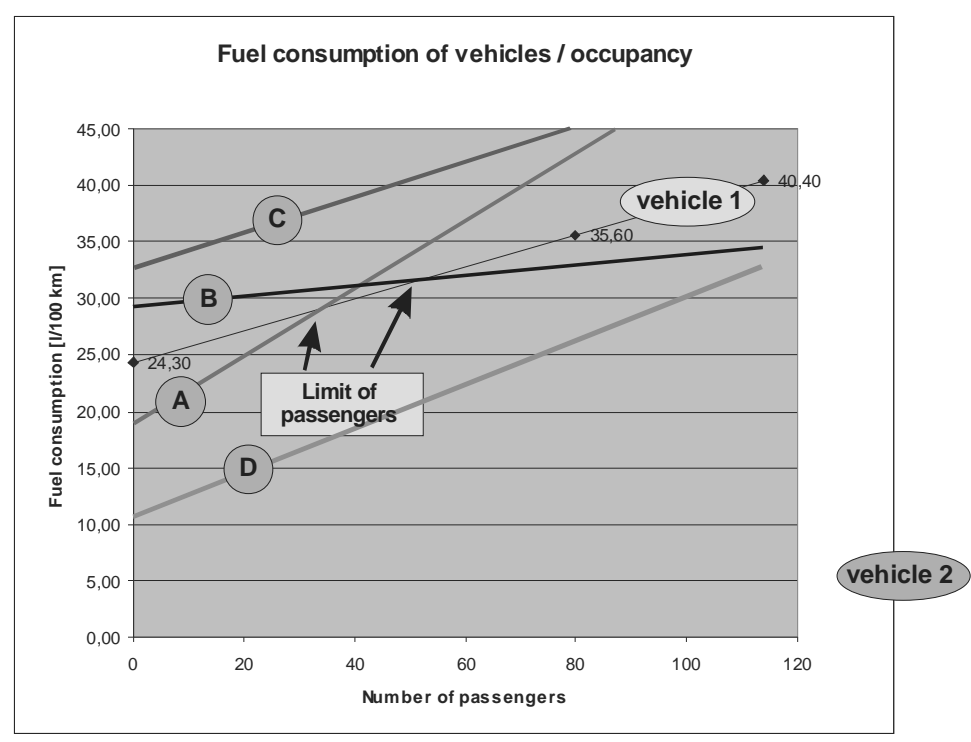

Figure 2: Point of intersection of curves of consumption of fuel dependant on the number of passengers with the same running speed. 

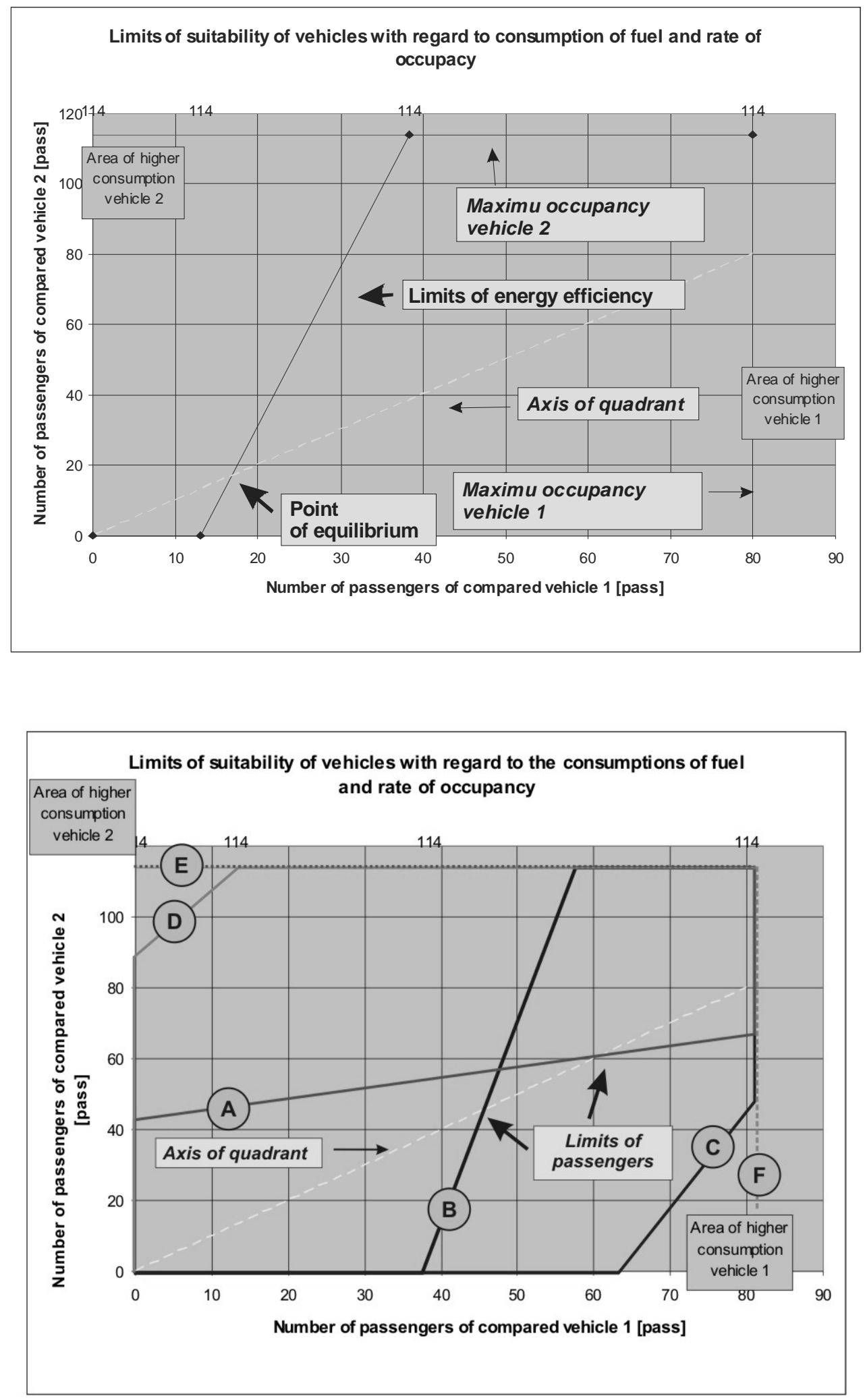

Figure 3, 4: A comparison of the most widespread railway unit series 800 or 810 of the Czech Railways and the standard buses Karosa; they both have about 44 seats and we suppose the same running speed. 
Table 2: Limits of suitability of vehicles with regard to the consumption of fuel and rate of occupancy

\begin{tabular}{|c|c|}
\hline Vehicle 1 (x1) & Vehicle $2(x 2)$ \\
\hline Bus Karosa C 734 & Railway unit 810 \\
\hline \multicolumn{2}{|c|}{$x 1=13,679+0,223 \times 2$} \\
\hline Bus Karosa C 732 & Railway unit 810 \\
\hline \multicolumn{2}{|c|}{$x 1=9,535+0,223 \times 2$} \\
\hline Bus Karosa C 934 & Railway unit 810 \\
\hline \multicolumn{2}{|c|}{$x 1=12,914+0,223 \times 2$} \\
\hline Articulated Bus Karosa & Railway unit $810+1$ towed $\mathrm{c}$. \\
\hline \multicolumn{2}{|c|}{$\mathrm{x} 1=14,265+0,216 \times 2$} \\
\hline Bus Karosa C 734 & Railway unit $810+1$ towed $\mathrm{c}$. \\
\hline \multicolumn{2}{|c|}{$\mathrm{x} 1=70,158+0,223 \times 2$} \\
\hline $2 \times$ Bus Karosa C 734 & Railway unit $810+1$ towed $\mathrm{c}$. \\
\hline \multicolumn{2}{|c|}{$x 1=-46,29+0,224 \times 2$} \\
\hline
\end{tabular}

\section{NECESSARY DENSITY OF TRAFFIC}

In the Czech Republic there are now 135 railway lines designated as local and regional lines. The annual average on the lines with the highest used capacity of trains (most occupied trains) have been trains with 14.5 passengers (six lines); this indicates that during the peak hours there are some lines with such highly occupied trains that the energy (and emission) efficiency is higher than in bus traffic. The majority of trains are not occupied enough to be more environmentally efficient than buses or even cars.

In all modes of ground transport, there are large costs of infrastructure. In the case of local and regional railway lines, it is necessary to operate the minimum number of trains to cover the costs of their tracks - naturally, in case of local and regional lines with subsidies on account of public services in the general interests, but on a level bearable for public co-funding.

In the Figure below there is a graph describing the yearly average number of passengers in a local or regional train for last year.

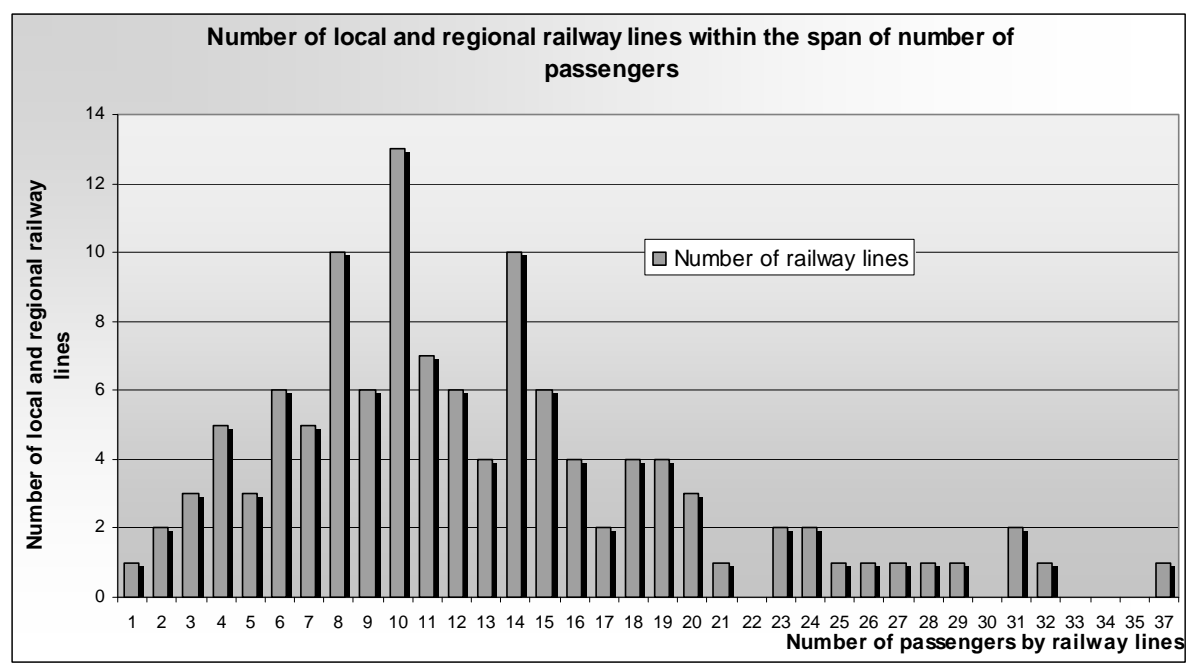

Figure 5: Yearly average number of passengers in a local or regional train. 


\section{OTHER TOOLS TO SUPPORT RAILWAYS}

At the time of the first Pan-European Transport Conference a parole was pronounced: "So much liberalization that is possible, so many regulations that is necessary". Is it still guilty? Is the consent with state aid approved by the Council of ministers, followed up by the European Commission, the only possible cure to help the railways? Could administrative tools be introduced to add the number of passengers and frequencies of passenger trains to make railways, from the point of view of energy and the emissions of greenhouse gases, more environmentally friendly than buses or, in general, road transport? Would it be acceptable by the European Court of Justice?

\section{AND OTHER POSSIBILITIES}

The local and regional lines are historical monuments. Is it possible to evaluate them not only from the point of view of economically evaluated means of transport? The stations in the very centres of towns and villages could be very desirable and could be used in favour of centres of tourism or they could be used for other lucrative business unconnected with railway transport. It is preferable to change them into centres of tourist areas - with stations converted partly into boarding houses, restaurants, and other supplementary activities connected with travelling, tourism, recreation, resort or other supplementary activities. Is it possible? Without such a transformation of part of the activities with a supplementary income, a predominant part of these lines could be abolished.

\section{REFERENCES}

[1] Bickel, P. \& Friedrich, R. Methodology 2005, update Commission; P. Biskel et all., Stuttgart 2006.

[2] Coll. BIVŠ and external associates: The evaluation of the economic impact of delays of construction of selected road communications. Study for Ministry of Transport 2008.

[3] INFRAS, CE Delft, Fraunhofer Gesellschaft - ISI, University of Gdansk. Handbook of estimation of external costs in the transport sector. Within the study Internalisation Measures and Polices for All external cost of Transport (IMPACT). Version 1.0. Delft December 19th 2007 and 1.1 February 2008.

[4] Peltrám A. \& Drahotský I. Enforcing vehicles with the lower influence on the environment. Doprava, vol. 50, iss. 6, pp. 3-4.

[5] Accepted revised proposal for a Directive of the European Parlament and of the Council on the promotion of clean and energy efficient road transport vehicles (IP/08/1570, $\mathrm{COM} / 2007817$ final. 